\title{
Violência obstétrica: questões conceituais a partir de um estudo bibliográfico na plataforma SciELO Brasil
}

\section{Obstetric violence: conceptual issues from a bibliographic study in the SciELO Brasil database}

\author{
Helena Guimarães Gasperin \\ Universidade Estadual de Ponta Grossa - UEPG - Ponta Grossa - Brasil \\ helenaggasperin@gmail.com \\ Mirian Cristina Ribas \\ Universidade Estadual de Ponta Grossa - UEPG - Ponta Grossa - Brasil \\ ribas.mi@hotmail.com \\ Sílvia Elaine da Silva \\ Universidade Estadual de Ponta Grossa - UEPG - Ponta Grossa - Brasil \\ silviaelainedasilva@gmail.com \\ José Augusto Leandro \\ Universidade Estadual de Ponta Grossa - UEPG - Ponta Grossa - Brasil \\ joseaugustoleandro@gmail.com
}

\section{Resumo}

O objetivo deste artigo é apresentar uma revisão de literatura acerca da produção científica sobre a temática da violência obstétrica disponível na plataforma SciELO Brasil. Analises como esta vem sendo discutida, com especial atenção para a problematização da questão conceitual. Por meio do estudo exploratório, utilizando as técnicas de revisão bibliográfica e pesquisa documental, verificou-se que inexiste um consenso com relação à conceituação de violência obstétrica, uma vez que se trata de uma concepção ampla e complexa, bem como constatou-se que a discussão acadêmica é bastante recente, evidenciando diálogos com a literatura internacional, em particular com autores da América Latina.

Palavras-chave: violência obstétrica, parto e nascimento, direitos sexuais e reprodutivos, revisão de literatura.

\section{Abstract}

The article's aim is to present a review of how the scientific literature has discussed the theme of obstetric violence available on the SciELO Brazil platform. The text analyzed how the subject has been discussed, focusing mainly on the problematization of the conceptual issue. Through the exploratory study, using literature review and documentary research techniques, it was found that there is no consensus regarding the conceptualization of obstetric violence, since it is a broad and complex conception, and it was found that the academic discussion is quite recent, showing dialogues with the international literature, in particular with Latin American authors. 
Keywords: obstetric violence, parturition and birth, sexual and reproductive rights, literature review.

\section{Introdução}

A medicina passou por muitas transformações ao longo do tempo e o processo de parto e nascimento foi impactado por elas, como resultado da institucionalização e da medicalização que ganharam força paulatinamente. Com isso, impulsionando um modelo cada vez mais dependente de processos tecnológicos e implicando em um padrão de atendimento tipicamente industrial, por meio de uma perspectiva tecnocrática, privilegiando assim, a rapidez em que acontecem os nascimentos.

Em seus estudos, Foucault discorre sobre o tema tratando esse fenômeno como "medicalização indefinida", fruto de um processo que se iniciou ao final do século XIX e que se mantém até a atualidade, sendo caracterizado por uma extrapolação da ciência médica à vida como um todo, onde nada é exterior e alheio ao saber médico (ZORZANELLI; CRUZ, 2018).

$\mathrm{O}$ que antes era compreendido como um acontecimento natural, sendo percebido como um momento familiar e íntimo, cujo foco era voltado especialmente para a parturiente, passou a ser realizado dentro do ambiente hospitalar, sob influência das relações de poder de modelo de cuidado masculino. Por consequinte, as necessidades da mulher passaram a ser menosprezadas, sob o domínio de práticas bastante intervencionistas (PONTES et al., 2014).

Nesse passo, a medicalização ocorrida no processo de parto ocasionou sua reestruturação, remodelando os papéis, de modo que a parturiente passou de protagonista do momento para mera coadjuvante. No âmbito da relação médico-paciente, a mulher teve seus desejos e decisões sobre esse momento postos em segundo plano, quando não totalmente suprimidos e desprezados (SEIBERT et al, 2005).

E com essa redução do processo de parto a uma símile linha de produção, a mulher que já tinha sua autonomia fraca perante os profissionais e as instituições de saúde, acabou por tê-la ainda mais fragilizada, acarretando intervenções excessivas e violações de direitos, em um fenômeno que foi intitulado como violência obstétrica (SILVA, 2017).

$\mathrm{Na}$ América Latina, a Venezuela foi pioneira na utilização do termo, sendo o primeiro país a adotar a expressão ao legislar sobre o tema no ano de 2007, como resultado das reivindicações do movimento feminista e do processo de reconhecimento dessa forma de violência contra a mulher como um problema público, social e político (SENA; TESSER, 2017). O assunto seguiu ganhando visibilidade na segunda década do século XXI, provocando debates em várias áreas, seguindo como um assunto ainda controverso, mas com sua relevância ratificada pela Organização Mundial da Saúde, que a classificou como problema de saúde pública (DINIZ et al., 2015).

Já no Brasil, uma pesquisa de abrangência nacional realizada pela Fundação Perseu Abramo em parceria com o Serviço Social do Comércio - SESC evidenciou que uma em cada quatro mulheres, ou seja, uma razão de $25 \%$ delas, foi vítima de violência obstétrica (VENTURI; GODINHO, 2013), evidenciando-se a gravidade do problema.

No campo acadêmico, o que se verifica é que a violência obstétrica tem sido tomada como objeto de estudos tão somente a partir de 2010. A proposta deste texto é a realização de uma revisão de literatura, a partir da base de dados Scielo Brasil a respeito da temática, ressaltando sua base teórica fundamental, suas especificidades e também possíveis convergências e divergências. 


\section{Metodologia}

Este estudo caracteriza-se como pesquisa exploratória e bibliográfica, de referenciais teóricos e metodológicos acerca da violência obstétrica, amparada por meio do método dedutivo. Conforme Gil (2008, p. 9) expõe "parte de princípios reconhecidos como verdadeiros e indiscutíveis e possibilita chegar a conclusões de maneira puramente formal, isto é, em virtude unicamente de sua lógica."

O trabalho é caracterizado como uma a pesquisa exploratória por ter como objetivo de proporcionar uma visão geral acerca de determinado fato, como aduz Gil (2008) a finalidade desse tipo de pesquisa é "[...] desenvolver, esclarecer e modificar conceitos e ideias, tendo em vista a formulação de problemas mais precisos ou hipóteses pesquisáveis para estudos posteriores. De todos os tipos de pesquisa, estas são as que apresentam menor rigidez no planejamento." (GIL, 2008, p. 27). E como uma pesquisa bibliográfica, pois esse tipo de pesquisa "é desenvolvida a partir de material já elaborado, constituído principalmente de livros e artigos científicos. Embora em quase todos os estudos seja exigido algum tipo de trabalho desta natureza, há pesquisas desenvolvidas exclusivamente a partir de fontes bibliográficas" (GIL, 2008, p. 50), como é o caso do presente artigo.

Dessa forma, fez-se uma análise da produção científica sobre o tema central 'Violência Obstétrica' disponível na plataforma de dados SciELO Brasil (http://www.scielo.br). Para a busca utilizou-se como palavra-chave "violência obstétrica", sendo que se selecionou todos os artigos encontrados, não havendo critérios de exclusão.

A plataforma SciELO foi escolhida, tendo em vista, o padrão de qualidade na propagação das produções cientificas que apresenta, por se tratar de uma plataforma em que faz circular a ciência, sendo a base de dados mais acessada e procurada quando se trata da busca em artigos cientificos, que, em sua maioria, são de livre acesso.

Ao realizar a busca, encontrou-se o total de doze artigos, sendo dez deles em português e dois em espanhol, de modo que não foi necessária a utilização de filtros de pesquisa. Destes, oito possuem o termo violência obstétrica em seu título e nas palavraschave, e quatro apresentam o termo apenas entre as palavras-chave. Após essa seleção, realizou-se a leitura dos doze artigos na íntegra e em seguida, fez-se uma análise individual do modo em que se apresenta o termo violência obstétrica e como este é conceitualmente exposto.

As questões que conduziram esta pesquisa foram: "Quando emergem artigos sobre violência obstétrica no Brasil? Como essa produção vem sendo realizada em termos teóricos-metodológicos? Quais pontos de convergência e divergência podem ser observados na produção acadêmica? Que áreas do conhecimento têm se interessado pelo tema? Há diálogo internacional nesta produção?". Tomando-as como ponto de partida, foi realizada uma investigação dos textos encontrados, cujos resultados da pesquisa serão apresentados e discutidos no decorrer dos próximos itens.

\section{Resultados}

O Quadro 1 apresenta um resumo geral do que se trata cada artigo encontrado na plataforma SciELO, base para a análise para os resultados desse trabalho. Também é possível verificar o título, os autores dos artigos, bem como a revista e a data em que foram publicados.

Quadro 1: Resumo dos trabalhos analisados

\begin{tabular}{|c|c|c|c|}
\hline Artigo & Autores & Periódico & $\begin{array}{c}\text { Época da } \\
\text { publicação }\end{array}$ \\
\hline
\end{tabular}




\begin{tabular}{|c|c|c|c|}
\hline $\begin{array}{c}\text { "Daí você nasceu minha filha": análise } \\
\text { discursiva crítica de uma carta ao } \\
\text { obstetra }\end{array}$ & $\begin{array}{l}\text { Jacqueline Fiuza da } \\
\text { Silva Regis e Viviane } \\
\text { de Melo Resende }\end{array}$ & Delta & Jun./dez. 2015 \\
\hline $\begin{array}{l}\text { O dilema de uma prática: experiências } \\
\text { de aborto em uma maternidade } \\
\text { pública de Salvador - Bahia }\end{array}$ & $\begin{array}{l}\text { Cecilia McCallum, } \\
\text { Greice Menezes e Ana } \\
\text { Paula dos Reis }\end{array}$ & $\begin{array}{l}\text { História, Ciências, } \\
\text { Saúde - } \\
\text { Manguinhos }\end{array}$ & Jan./mar. 2016 \\
\hline $\begin{array}{l}\text { La gineco-obstetricia en México: entre } \\
\text { el "parto humanizado" y la violência } \\
\text { obstetrica }\end{array}$ & Maria Raquel Pozzio & $\begin{array}{l}\text { Revista Estudos } \\
\text { Feministas }\end{array}$ & Jan./abr. 2016 \\
\hline $\begin{array}{c}\text { Dime quién lo define y te diré si es } \\
\text { violento: Reflexiones sobre la violencia } \\
\text { obstétrica }\end{array}$ & Belén Castrillo & $\begin{array}{l}\text { Sexualidad, Salud } \\
\text { y Sociedad }\end{array}$ & Dez. 2016 \\
\hline $\begin{array}{l}\text { Violência obstétrica no Brasil e o } \\
\text { ciberativismo de mulheres mães: } \\
\text { relato de duas experiências }\end{array}$ & $\begin{array}{l}\text { Ligia Moreira Sena e } \\
\text { Charles Dalcanale } \\
\text { Tesser. }\end{array}$ & $\begin{array}{l}\text { Interface } \\
\text { (Botucatu) }\end{array}$ & Jan./mar. 2017 \\
\hline $\begin{array}{c}\text { Autonomia para quem? O discurso } \\
\text { médico hegemônico sobre a violência } \\
\text { obstétrica no Brasil }\end{array}$ & $\begin{array}{l}\text { Luciana Aparecida } \\
\text { Palharini }\end{array}$ & Cadernos Pagu & Dez. 2017 \\
\hline $\begin{array}{l}\text { Violência obstétrica em maternidades } \\
\text { públicas do estado do Tocantins }\end{array}$ & $\begin{array}{c}\text { Liana Barcelar } \\
\text { Evangelista } \\
\text { Guimarães, Eline } \\
\text { Jonas e Leila Rute } \\
\text { Oliveira Gurgel do } \\
\text { Amaral. }\end{array}$ & $\begin{array}{l}\text { Revista Estudos } \\
\text { Feministas }\end{array}$ & Jan./abr. 2018 \\
\hline $\begin{array}{l}\text { O funcionamento discursivo de } \\
\text { Campanhas sobre a violência no } \\
\text { parto: testemunho, violência e silêncio }\end{array}$ & $\begin{array}{l}\text { Aline Fernandes de } \\
\text { Azevedo Bocchi }\end{array}$ & $\begin{array}{l}\text { Linguagem em } \\
\text { (Dis)curso }\end{array}$ & Jan./abr. 2019 \\
\hline $\begin{array}{c}\text { Como superar a cultura da } \\
\text { imobilização física das } \\
\text { parturientes? Resultados parciais de } \\
\text { estudo de intervenção em São Paulo, } \\
\text { SP, Brasil }\end{array}$ & $\begin{array}{c}\text { Denise Yoshie Niy, } \\
\text { Valéria Clarisse de } \\
\text { Oliveira, Luma } \\
\text { Rodrigues de Oliveira, } \\
\text { Bruna Dias Alonso, } \\
\text { Carmen Simone Grilo } \\
\text { Diniz }\end{array}$ & $\begin{array}{l}\text { Interface } \\
\text { (Botucatu) }\end{array}$ & Maio 2019 \\
\hline $\begin{array}{l}\text { Percepção dos médicos sobre a } \\
\text { violência obstétrica } \\
\text { na sutil dimensão da relação humana } \\
\text { e médico-paciente }\end{array}$ & $\begin{array}{l}\text { Maristela Muller Sens } \\
\text { e Ana Maria Nunes de } \\
\text { Faria Stamm }\end{array}$ & $\begin{array}{l}\text { Interface } \\
\text { (Botucatu) }\end{array}$ & Jul. 2019 \\
\hline $\begin{array}{c}\text { Experiências de mulheres no gestar e } \\
\text { parir fetos } \\
\text { anencéfalos: as múltiplas faces da } \\
\text { violência obstétrica }\end{array}$ & $\begin{array}{l}\text { Iulia Bicu Fernandes, } \\
\text { Paulo Alexandre de } \\
\text { Souza São Bento e } \\
\text { Rozânia Bicego Xavier }\end{array}$ & $\begin{array}{l}\text { Interface } \\
\text { (Botucatu) }\end{array}$ & Ago. 2019 \\
\hline $\begin{array}{l}\text { A percepção dos médicos sobre as } \\
\text { dimensões da violência obstétrica e/ou } \\
\text { institucional }\end{array}$ & $\begin{array}{l}\text { Maristela Muller Sens } \\
\text { e Ana Maria Nunes de } \\
\text { Faria Stamm }\end{array}$ & $\begin{array}{l}\text { Interface } \\
\text { (Botucatu) }\end{array}$ & Ago. 2019 \\
\hline
\end{tabular}

Fonte: Autores (2019)

Inicialmente, faz-se necessário ressaltar que, ainda que todos tenham como ponto de convergência a temática da violência obstétrica, cada um dos trabalhos possui suas particularidades, fazendo uso de um arcabouço teórico integrado por diferentes autores, utilizando-se de abordagens distintas para trabalhar 0 assunto. Sob este prisma, discutiremos as especificidades de cada um desses autores. 
No trabalho de Regis e Resende (2015), a violência obstétrica foi refletida por meio de uma carta enviada a um obstetra por uma mãe. A partir deste estudo, as autoras deslindam a composição retórica do texto, em que a expressão de sentimentos de indignação diante do procedimento de cesariana ao qual esta fora submetida é o cerne. $O$ documento é considerado como registro de um cenário que, embora bastante específico, talvez não seja tão incomum. Analisa-se a representação discursiva do parto com a problematização dos sentimentos da referida mulher sobre os procedimentos realizados.

McCallum, Menezes e Reis (2016) analisaram a violência obstétrica por meio da questão do aborto, sob a perspectiva de onze mulheres internadas em uma maternidade pública de Salvador (BA) e a relação dessas com os profissionais de saúde. Apresentaram como a estruturação do atendimento e os processos de simbolização afetam as mulheres e suas experiências, bem como evidenciam que a violência sofrida é estrutural e não apenas ligada a questões individuais.

A proposta de Pozzio (2016) é de abordar as diferentes posturas dos atores em torno das práticas de humanização do parto na busca pela diminuição dos casos de violência obstétrica, com foco especial nas mulheres obstetras e ginecologistas. Seu viés avaliativo parte da perspectiva antropológica da feminilização da profissão que vem ocorrendo na contramão da masculinização histórica que até entao caracterizou a profissão.

Castrillo (2016) discute a definição de violência obstétrica por meio de uma análise sócio-antropológica, comparando definições objetivas (jurídicas, políticas, acadêmicas) e subjetivas (produzidas pela sociedade civil), sintetizando a existência de uma disputa sobre a legitimidade de sua definição. A autora aponta o estabelecimento de certos significados subjetivos a determinadas práticas obstétricas, evidenciando a disputa de poderes existente e as articulações envolvidas.

O trabalho de Sena e Tesser (2017) descreve o ciberativismo de mulheres mães brasileiras, com o objetivo de relacionar o enfrentamento da violência obstétrica no país a essa nova estratégia e proposta de mobilização social contemporânea. Debate a necessidade de novas pesquisas acadêmicas sobre o tema e a relevância de novas tecnologias como ferramentas de auxílio às pesquisas, destacando o importante papel da internet como possibilitadora de interação e participação, sendo instrumentos estratégicos de ativismo.

A exposição de Palharini (2017) investiga o tema da violência obstétrica por meio da análise do discurso nos posicionamentos dos órgãos representativos da classe médica acerca dos debates atuais sobre a temática. Neste sentido, a autora constatou nos textos vinculados por essas instituições que há uma rejeição à existência da violência obstétrica por parte dos profissionais. Seus argumentos são envoltos por uma retórica de cientificidade, desqualificando todo o posicionamento contrário e evidenciando uma vontade de exclusão da mulher do processo decisório. Dessa feita, a mulher torna-se mero objeto das intervenções e prescrições e ignorando que esta faz parte da relação médico-paciente como sujeito, ficando à mercê de uma estrutura bastante autoritária.

Já a perspectiva de Guimarães, Jonas e Amaral (2018) tem como base uma pesquisa desenvolvida com 14 maternidades públicas do estado do Tocantins, em que as mulheres entrevistadas expuseram suas percepções sobre a violência obstétrica, que apresentou-se ligada à falta de qualidade e acolhimento na assistência institucional. Além disso, a pesquisa constata o descumprimento de normativas importantes e violações de direitos e evidenciando-se a necessidade do comprometimento dos profissionais de saúde com a promoção do cuidado e dos direitos das mulheres.

Bocchi (2019) pondera sobre as formas de significar a violência obstétrica por meio da análise do discurso, através de recortes em duas campanhas de combate a este tipo de violência, sendo uma brasileira e uma argentina, com a problematização dos modos como essas campanhas são constituídas, formuladas e veiculadas, enquanto produtoras 
de diferentes sentidos. Ressalta que a constituição do discurso sobre a violência obstétrica se mostra como uma trama que necessita de uma reconstrução como forma de enfrentamento a esse tipo de violência.

O artigo de Niy et al. (2019) expõe que a cultura de imobilização física no processo do parto ainda é um desafio no Brasil, identificando facilitadores e obstáculos da liberdade de posição em um projeto-piloto realizado no município de São Paulo (SP). A percepção de gestores, profissionais de saúde e usuárias sobre a questão da restrição de movimentos e posição durante o trabalho de parto foi analisada e debatida frente à violência obstétrica, com a discussão de ações que podem contribuir para promover mudanças nesses espaços.

A pesquisa de Sens e Stamm (2019a) visa identificar a percepção dos obstetras que prestam assistência ao parto em uma maternidade humanizada do sul do Brasil. Constatou-se que, a partir da dimensão da relação humana médico-paciente, a percepção desses profissionais é subjetiva, abarcando diferentes aspectos, vez que a violência obstétrica é eivada de sutilezas. Com isso, as autoras concluem que a relação médicopaciente é mediada por sentimentos, emoções e julgamentos, e que além das mulheres serem vítimas de algum tipo de violência durante o parto, os médicos, também, se colocam enquanto vítimas de violência durante o exercício profissional, seja relacionado a estrutura institucional e a precarização do trabalho. Ainda, os obstetras trazem como superação da violência obstétrica, ações em educação e informação, além de adequação da estrutura física e a responsabilização de outros agentes envolvidos no processo do parto.

Fernandes, São Bento e Xavier (2019) retratam a experiência de 12 mulheres e as violências sofrida por essas gestantes de fetos anencéfalos ${ }^{1}$. Por meio da pesquisa, constatou-se que, desde o momento da descoberta da anencefalia até a internação para interrupção da gestação e/ou realização do parto, essas mulheres vivenciaram violências das mais diversas maneiras. Dentre elas, destaca-se a peregrinação e a negação do atendimento, falta de informação e acolhimento, abandono e, de forma comum a todas as entrevistadas, o julgamento moral recebido de familiares, da instituição de saúde e dos profissionais responsáveis pelos procedimentos em razão das escolhas que essas mulheres tiveram.

Ainda, Sens e Stamm (2019b) realizaram uma pesquisa com 23 médicos ginecologistas e obstetras de uma maternidade pública humanizada e de ensino, com o intuito de analisar a percepção desses profissionais sobre a violência obstétrica a partir do viés da reflexão das dimensões individual, institucional e da relação humana. Este fenômeno é reconhecido por todos esses profissionais, que, entretanto, criticam a nomenclatura utilizada e a forma como esta responsabiliza o obstetra em relação a problematização do tema. $\mathrm{Na}$ análise das dimensões propostas, constatou-se que são fatores propícios a violência obstétrica, na individual têm-se a prática profissional desatualizada e não embasada em evidências; na institucional caracteriza a falta de estrutura e a rotina automatizada e na relação humana a autonomia feminina é tida como um direito ético e inquestionável, porém é limitado conforme estabelece o profissional.

\section{Discussão}

Embora os artigos sejam diferentes, todos desenvolvem a temática da violência obstétrica com maior ou menor expressividade. Nenhum dos trabalhos nega ou minimiza as experiências relatadas pelas mulheres, partindo dessas vivências para debater 0

\footnotetext{
1 "A anencefalia [...] é uma malformação congênita decorrente da falha no fechamento da extremidade superior do tubo neural durante a quarta semana de embriogênese, resultando na ausência total ou parcial do cérebro e do crânio, deixando o cérebro exposto, quando este é desenvolvido parcialmente". (FERNANDES; SÃO BENTO; XAVIER, 2019, p.2)
} 
fenômeno, de modo que todos os trabalhos admitem a existência da violência obstétrica, sendo que alguns apenas são mais sucintos, enquanto outros discutem o assunto de maneira mais aprofundada.

Faz-se necessário ressaltar que os estudos apresentados foram escritos quase que totalmente por mulheres, cujas formações variam entre as áreas da saúde, das ciências sociais e educação, tendo sido publicados em periódicos de áreas também variadas sendo alguns deles de cunho feminista, demonstrando a interdisciplinaridade em que a temática está envolvida.

A primeira constatação significativa extraída da análise realizada é a conceituação dos autores para a violência obstétrica, sendo que todos partem de uma determinada realidade vivida no ciclo gravídico-puerperal, observando-se a inexistência de divergências concretas nesse sentido, mas sim diferenças de amplitude e completude entre os conceitos encontrados. Como exemplo, tem-se o fato de nenhuma das concepções trazidas abordar a questão do aborto, ainda que um texto seja inteiramente dedicado a tratar da ocorrência de violência obstétrica nessa área.

Imprescindível se faz analisar de forma individual os conceitos de violência obstétrica empregados pelos autores nos textos pesquisados, com o intuito de questionar quais as percepções acerca desse fenômeno, de maneira que, a partir dessa compreensão, seja possível assimilar a narrativa das publicações de maneira mais completa.

Regis e Resende (2015, p. 576) se valem do conceito de D'Gregorio (2010, p. 201) ao expor que:

A violência obstétrica diz respeito à apropriação do corpo e dos processos reprodutivos das mulheres por profissionais de saúde de maneira expressa por tratamento desumano, pelo uso abusivo de medicação, pela conversão de processos fisiológicos em processos patológicos, acarretando com isso perda de autonomia a da habilidade de decidir livremente sobre seus corpos e sexualidade, impactando negativamente a qualidade de vida das mulheres.

Já McCallum, Menezes e Reis (2016,) em seu artigo não aprofundam a respeito da questão conceitual da violência obstétrica, apenas indicam-na como "expressão que tem sido adotada por estudos que, principalmente, analisam as experiências de parto". (McCALLUM; MENEZES; REIS, 2016, p. 40).

Já Pozzio (2016) parte da ideia de que violência obstétrica é um tipo de violência que afeta a saúde reprodutiva e que está frequentemente presente na atenção convencional dos serviços institucionais e privados, sendo produto do patriarcado, que se manifesta na legitimação de procedimentos como a apropriação do corpo da mulher e um tratamento desumanizador e uma patologização de seus processos naturais.

Castrillo (2016) faz a discussão da violência obstétrica utilizando-se de conceitos objetivos e subjetivos, destacando-se duas das definições objetivas. A primeira delas é a presente na lei argentina sobre o tema, a Lei 26.485/2009, baseada no texto da lei venezuelana, em que a violência obstétrica seria aquela que o profissional de saúde exerce sobre o corpo e os processos reprodutivos das mulheres expressados pelo tratamento desumanizado, abuso da medicalização e patologização dos processos naturais. A segunda seria a definição de Medina (2010), em que a autora define violência obstétrica como um conjunto de violações aos direitos humanos e reprodutivos das mulheres na esfera da atenção à gestação, parto e puerpério nos serviços de saúde públicos e privados, como produto de um emaranhado multifatorial em que convergem a violência institucional e a violência de gênero.

No entendimento de Sena e Tesser (2017, p. 209), "violência obstétrica é uma expressão que agrupa as formas de violência e danos originados no cuidado obstétrico profissional". O que se verifica é que o conceito é trazido de uma forma pretensamente 
totalizante, vez que, de maneira bastante genérica, visa agrupar os possíveis tipos e violações.

Por sua vez, Palharini (2017) utiliza o conceito de Tesser et al (2015, p. 3) baseado na lei venezuelana sobre o tema, a Lei 38.668/2007, em que:

\begin{abstract}
Entende-se por violência obstétrica a apropriação do corpo e dos processos reprodutivos das mulheres por profissional de saúde que se expresse por meio de relações desumanizadoras, de abuso de medicalização e de patologização dos processos naturais, resultando em perda de autonomia e capacidade de decidir livremente sobre seu corpo e sexualidade, impactando negativamente na qualidade de vida das mulheres.
\end{abstract}

A publicação de Guimarães, Jonas e Amaral (2018, p. 1-2), também retrata sobre a lei venezuelana 38.668/07, nesse sentido, apresentando sua conceituação de forma bastante abrangente, como sendo:

A expressão violência obstétrica define-se como qualquer conduta, ato ou omissão realizado por profissionais de saúde, tanto em instituição pública, quanto privada que, direta ou indiretamente, leva à apropriação indevida dos processos corporais e reprodutivos das mulheres. Expressa-se em tratamento desumano, abuso da medicalização e patologização dos processos naturais, levando à perda da autonomia e capacidade para decidir livremente sobre seu corpo e sexualidade, impactando negativamente a qualidade de vida.

Bocchi (2019) lança mão do conceito divulgado pela Defensoria Pública do Estado de São Paulo, o qual claramente tem sua raiz na lei venezuelana, como sendo ela "[...] apropriação do corpo e processos reprodutivos das mulheres pelos profissionais da saúde". (SÃO PAULO, 2013, s.p.).

Niy et al. (2019, p. 3) discorrem sobre o controle dos corpos femininos no momento do parto e, ao unir concepções de diversos autores, asseveram que:

\footnotetext{
Essa apropriação do corpo das mulheres e de seus processos reprodutivos também tem sido denominada violência obstétrica, ou abuso, desrespeito e maustratos, e a cada dia crescem as evidências de que esse fenômeno está intimamente ligado à baixa qualidade da assistência e a piores desfechos, inclusive em serviços especializados.
}

Sens e Stamm (2019a) buscam nas legislações venezuelana e argentina definição factual de violência obstétrica, sendo esta "a apropriação do corpo e processos reprodutivos das mulheres por profissional de saúde, que se expressa em um trato desumanizador e abuso da medicalização e patologização dos processos naturais". (SENS; STAMM, 2019a, p. 3)

Fernandes, São Bento e Xavier (2019) não trazem um conceito exato do que vem a ser violência obstétrica, expondo de forma mais informativa que "esta acontece no momento da gestação, parto, nascimento e/ou pós-parto, inclusive no atendimento ao abortamento, e pode ser classificada em violência institucional, moral, física, psicológica, verbal e sexual."

Por fim, Sens e Stamm (2019b) utilizam o mesmo conceito já discutido em trabalho anterior, porém desta vez apenas referenciando-o como retirado do texto legal venezuelano.

Assim, é possível verificar que a maioria das definições utilizadas nos trabalhos são emprestadas de diversos autores, sendo que apenas três textos trazem conceitos próprios dos autores em sua composição, como indica o Quadro 2.

Quadro 2: Conceito dos trabalhos analisados 


\begin{tabular}{|c|c|c|}
\hline Autores & $\begin{array}{l}\text { Época da } \\
\text { publicação }\end{array}$ & Conceito próprio ou emprestado? \\
\hline $\begin{array}{l}\text { Jacqueline Fiuza da Silva Regis e } \\
\text { Viviane de Melo Resende }\end{array}$ & Jun./ dez. 2015 & Emprestado de D'Gregorio (2010). \\
\hline $\begin{array}{c}\text { Cecilia McCallum, Greice Menezes e } \\
\text { Ana Paula dos Reis }\end{array}$ & Jan./ mar. 2016 & Próprio. \\
\hline Maria Raquel Pozzio & Jan./ abr. 2016 & $\begin{array}{l}\text { Emprestado de Almaguer González, } \\
\text { Garcia Ramírez e Vargas Vite (2010). }\end{array}$ \\
\hline Belén Castrillo & Dez. 2016 & $\begin{array}{c}\text { Emprestado de Medina (2010) e da lei } \\
\text { argentina. }\end{array}$ \\
\hline $\begin{array}{c}\text { Ligia Moreira Sena e Charles Dalcanale } \\
\text { Tesser }\end{array}$ & Jan./ Mar. 2017 & $\begin{array}{c}\text { Emprestado de D'Gregorio (2010), Diniz } \\
\text { e D'Oliveira (2002) e Diniz e D' Oliveira } \\
\text { (1998). }\end{array}$ \\
\hline Luciana Aparecida Palharini & Dez. 2017 & Emprestado de Tesser et al. (2015). \\
\hline $\begin{array}{c}\text { Liana Barcelar Evangelista Guimarães, } \\
\text { Eline Jonas e Leila Rute Oliveira Gurgel } \\
\text { do Amaral }\end{array}$ & Jan./ abr. 2018 & $\begin{array}{l}\text { Emprestado da lei venezuelana e de } \\
\text { D'Oliveira, Diniz e Schraiber (2002). }\end{array}$ \\
\hline Aline Fernandes de Azevedo Bocchi & Jan./ abr. 2019 & $\begin{array}{c}\text { Emprestado da Defensoria Pública do } \\
\text { Estado de São Paulo (São Paulo, 2013) } \\
\text { e da lei venezuelana. }\end{array}$ \\
\hline $\begin{array}{c}\text { Denise Yoshie Niy, Valéria Clarisse de } \\
\text { Oliveira, Luma Rodrigues de Oliveira, } \\
\text { Bruna Dias Alonso e Carmen Simone } \\
\text { Grilo Diniz }\end{array}$ & Maio 2019 & Próprio. \\
\hline $\begin{array}{c}\text { Maristela Muller Sens e Ana Maria } \\
\text { Nunes de Faria Stamm }\end{array}$ & Jul. 2019 & Leis venezuelana e argentina. \\
\hline $\begin{array}{c}\text { Lulia Bicu Fernandes, Paulo Alexandre } \\
\text { de Souza São Bento e Rozânia Bicego } \\
\text { Xavier }\end{array}$ & Ago. 2019 & Próprio. \\
\hline $\begin{array}{c}\text { Maristela Muller Sens e Ana Maria } \\
\text { Nunes de Faria Stamm }\end{array}$ & Ago. 2019 & Lei venezuelana. \\
\hline
\end{tabular}

Fonte: Autores (2019)

Destaca-se que alguns dos autores se utilizam da concepção trazida pela lei venezuelana para realizar sua conceituação, ainda que não mencionem expressamente que se trata desta fonte em seus trabalhos, observou-se que está sendo feita uma tradução livre do texto legislativo.

À vista disso, foi possível averiguar que trabalhar a concepção de violência obstétrica não é tarefa simples, implicando em certo grau de dificuldade de calibragem teórica, vez que se trata de fenômeno amplo, profundo e muito complexo, demandando muito cuidado em sua discussão.

Outro resultado notável identificado pela pesquisa diz respeito ao período de produção dos trabalhos, tratando-se de elaboração bastante recente, tendo ocorrido nos últimos quatro anos. Frise-se que quatro dos artigos em análise foram publicados após a polêmica ocasionada em razão do Ministério da Saúde do Brasil ter exarado despacho posicionando-se pela abolição do uso do termo violência obstétrica, no início do mês de maio de 2019, quando a temática ganhou mais destaque. Assim, o que se depreende é 
que a discussão que visava o apagamento da questão pela supressão do termo acabou por impulsionar um intenso debate e, com isso, a produção científica sobre a temática.

Ainda, foram identificadas várias convergências em relação aos autores utilizados como referencial teórico, visto que alguns se repetiram nos artigos analisados, conforme listado no Quadro 3.

Quadro 3: Autores mais citados nos artigos

\begin{tabular}{|c|c|c|c|c|}
\hline Nome do autor & Origem & Profissão & $\begin{array}{l}\text { Número de artigos } \\
\text { em que aparece }\end{array}$ & $\begin{array}{l}\text { Número de } \\
\text { trabalhos citados }\end{array}$ \\
\hline Carmen Simone Grilo Diniz & Brasil & $\begin{array}{c}\text { Médica e } \\
\text { pesquisadora }\end{array}$ & 08 & 13 \\
\hline Janaína Marques de Aguiar & Brasil & $\begin{array}{l}\text { Psicóloga e } \\
\text { pesquisadora }\end{array}$ & 08 & 04 \\
\hline $\begin{array}{c}\text { Ana Flávia Pires Lucas } \\
\text { D'Oliveira }\end{array}$ & Brasil & $\begin{array}{l}\text { Médica e } \\
\text { professora }\end{array}$ & 08 & 04 \\
\hline $\begin{array}{c}\text { Sonia Nussenzweig } \\
\text { Hotimsky }\end{array}$ & Brasil & $\begin{array}{l}\text { Professora e } \\
\text { pesquisadora }\end{array}$ & 07 & 05 \\
\hline Charles Dalcanale Tesser & Brasil & $\begin{array}{l}\text { Médico e } \\
\text { pesquisador }\end{array}$ & 07 & 03 \\
\hline Lilia Blima Schraiber & Brasil & $\begin{array}{c}\text { Médica e } \\
\text { pesquisadora }\end{array}$ & 06 & 02 \\
\hline Carmen Susana Tornquist & Brasil & $\begin{array}{l}\text { Professora e } \\
\text { pesquisadora }\end{array}$ & 05 & 04 \\
\hline $\begin{array}{l}\text { Rosa Maria Soares } \\
\text { Madeira Domingues }\end{array}$ & Brasil & $\begin{array}{c}\text { Médica e } \\
\text { pesquisadora }\end{array}$ & 05 & 03 \\
\hline Daphne Rattner & Brasil & $\begin{array}{c}\text { Médica e } \\
\text { pesquisadora }\end{array}$ & 04 & 02 \\
\hline Rogelio Pérez D’Gregorio & Venezuela & Médico & 04 & 01 \\
\hline Robbie Davis-Floyd & EUA & Antropóloga & 03 & 02 \\
\hline
\end{tabular}

Fonte: Autores (2019)

Além disso, é pertinente pontuar que os artigos de Palharini (2017), Guimarães, Jonas e Amaral (2018) e Sens e Stamm (2019a e 2019b) citam o texto de Sena e Tesser (2017), demonstrando a importância científica do referido trabalho. E a relevante pesquisa de abrangência nacional da Fundação Perseu Abramo em parceria com o SESC, aparece em quatro das publicações encontradas.

\section{Considerações finais}

A partir da discussão sobre os artigos encontrados na referida plataforma de dados, verificou-se que todos trazem, de forma ampla, um debate relacionado ao tema da violência obstétrica, que é explorado por diferentes perspectivas. O que se evidencia é que mesmo com aspectos variados, inclusive com dois dos textos trazendo um viés antropológico à discussão, eles acabam por não ser divergentes em seu cerne.

Sob uma mesma temática principal, as discussões dos trabalhos se mostram bastante heterogêneas e plurais, de modo que os resultados apresentam como a violência obstétrica pode ser analisada por diferentes prismas e formas, difundindo-se em questões e conclusões diversificadas.

Levando em consideração que a base de dados SciELO é um indicativo de produções de boa qualidade, tida como referência nas produções científicas, é 
decepcionante somente doze artigos terem sido encontrados abordando a palavra-chave 'violência obstétrica'. Constata-se que as produções acadêmicas a respeito dessa temática são, ainda, tímidas e não expressam a importância do debate sobre a temática, pois a discussão sobre parto e nascimento é antiga, entretanto a questão da violência obstétrica como objeto de estudo é bastante recente. Contudo, denota-se que o assunto esteve em evidência recentemente, em razão do despacho ${ }^{2}$ exarado pelo Ministério da Saúde, tendo em vista que o número de publicações cresceu de maneira significativa no presente ano.

Ainda, vale ressaltar que o androcentrismo científico é predominante na universidade brasileira, entretanto nota-se uma crescente predominância da produção feminina na academia, fazendo com que não seja surpresa que os artigos tenham sido escritos quase todos por mulheres.

Como visto nos trabalhos apresentados, o conceito de violência obstétrica é, via de regra, retirado de publicações de diferentes autores e/ou de legislações internacionais. Dessa forma, conclui-se que o próprio conceito de violência obstétrica ainda parece não estar totalmente consubstanciado, porquanto não há pesquisas suficientes que o desenvolvam de modo aprofundado, abarcando a realidade brasileira.

Ressalte-se que, a exemplo do afirmado acima, os doze artigos analisados se furtaram em articular o aborto na construção do conceito violência obstétrica, por mais que um destes trabalhos seja inteiramente voltado para o tema. A desvinculação do aborto da conceituação do fenômeno da violência obstétrica demonstra a existência de brechas em sua construção teórica e na identificação empírica das particularidades inerentes à prática.

A ampliação do debate sobre temas relativos à violência de gênero, como a violência obstétrica, demonstra-se fundamental em uma sociedade violenta e dominada por práticas e ideais machistas, como a brasileira. Dessa forma, o aumento dos estudos sobre a temática em nível básico e específico possibilitará que as violências de gênero tenham sua visibilidade ampliada, conduzindo à elaboração de legislações específicas visando coagir abusos, bem como, à modificação das representações sociais sobre a mulher, seu corpo e sua autonomia. Dessa forma, a comunidade científica como um todo possui um relevante papel político no desenvolvimento da temática, isto é, deve estimular debates sobre o reconhecimento e a prevenção às violências de gênero que abrangem o ciclo gravídico-puerperal.

\section{Referências}

ALMAGUER GONZÁLEZ, José Alejandro, GARCIA RAMÍREZ, Hernán, VARGAS VITE, Vicente. La violencia obstétrica: una forma de patriarcado em las instituciones de salud. Género y Saluden Cifras, v. 8, n. 3, p. 4-20, set./dez. 2010.

ARGENTINA. Ley 26.485, de 11 de marzo de 2009. Ley de protección integral para prevenir, sancionar y erradicar la violencia contra las mujeres en los ámbitos en que desarrollen sus relaciones interpersonales. Disponível em: <https://www.oas.org/dil/ esp/Ley_de_Proteccion_Integral_de_Mujeres_Argentina.pdf>. Acesso em: 21 maio 2019.

$\mathrm{BOCCHI}$, Aline Fernandes de Azevedo. O funcionamento discursivo de campanhas sobre a violência no parto: testemunho, violência e silêncio. Linguagem em (Dis)curso, Tubarão, v. 19, n. 1, p. 17-33, jan./abr. 2019.

\footnotetext{
2 Ver mais em: https://www.migalhas.com.br/arquivos/2019/5/art20190510-10.pdf.
} 
CASTRILLO, Belén. Dime quién lo define y te diré si es violento: reflexiones sobre la violencia obstétrica. Sexualidad, Salud y Sociedad, Rio de Janeiro, n. 24, p. 43-68, dez. 2016.

D'GREGORIO, Rogelio Pérez. Obstetric violence: A new legal term introduced in Venezuela. International Journal of Gynecology and Obstetrics, Londres, v. 111, n. 3, p. 201-202, dez. 2010.

D’OLIVEIRA, Ana Flávia Pires Lucas; DINIZ, Simone Grilo; SCHRAIBER, Lilia Blima. Violence against women in health-care institutions: an emerging problem. Lancet, v. 359, n. 9318, p. 1681-1685, maio 2002.

DINIZ, Simone Grilo; D'OLIVEIRA, Ana Flávia Pires Lucas. Gender violence and reproductive health. International Journal of Gynecology and Obstetrics, Londres, v. 63, n. 1, p. 33-42, dez. 1998.

DINIZ, Simone Grilo; SALGADO, Heloisa de Oliveira; ANDREZZO, Halana Faria de Aguiar; CARVALHO, Paula Galdino Cardin de; CARVALHO, Priscila Cavalcanti Albuquerque; AGUIAR, Cláudia de Azevedo; NIY, Denise Yoshie. Violência obstétrica como questão para a saúde pública no Brasil: origens, definições, tipologia, impactos sobre a saúde materna, e propostas para sua prevenção. Journal of Human Growth and Development, São Paulo, v. 25, n. 3, p. 377-384, 2015.

FERNANDES, Lulia Bicu; SÃO BENTO, Paulo Alexandre de Souza; XAVIER, Rozânia Bicego. Experiências de mulheres no gestar e parir fetos anencéfalos: as múltiplas faces da violência obstétrica. Interface (Botucatu), Botucatu, v. 23, 2019.

\section{GIL, Antonio Carlos. Métodos e Técnicas de Pesquisa Social. São Paulo: Atlas, 2008.}

GUIMARAES, Liana Barcelar Evangelista; JONAS, Eline; AMARAL, Leila Rute Oliveira Gurgel do. Violência obstétrica em maternidades públicas do estado do Tocantins. Revista Estudos Feministas, Florianópolis, v. 26, n. 1, p. 1-11, 2018.

MCCALLUM, Cecilia; MENEZES, Greice; REIS, Ana Paula dos. O dilema de uma prática: experiências de aborto em uma maternidade pública de Salvador, Bahia. História, Ciências, Saúde - Manguinhos, Rio de Janeiro, v. 23, n. 1, p. 37-56, jan./mar. 2016.

MEDINA, Graciela. Violencia obstétrica. Cap 4 en Informe de "Omisión y diferencia. DerechosReproductivosen México”. Grupo de información em reproducción elegida. 2010. Disponível em: http://informe.gire.org.mx/bibliografia.html. Acesso em: 20 maio 2019.

NIY, Denise Yoshie; OLIVEIRA, Valéria Clarisse de; OLIVEIRA, Luma Rodrigues de; ALONSO, Bruna Dias; DINIZ, Carmen Simone Grilo. Como superar a cultura da imobilização física das parturientes? Resultados parciais de estudo de intervenção em São Paulo, SP, Brasil. Interface (Botucatu), Botucatu, v. 23, e180074, 2019.

PALHARINI, Luciana Aparecida. Autonomia para quem? O discurso médico hegemônico sobre a violência obstétrica no Brasil. Cadernos Pagu, Campinas, n. 49, 2017.

PONTES, Monise Gleyce de Araujo; LIMA, Gigliola Marcos Bernando de; FEITOSA, Izauana Pereira; TRIGUEIRO, Janaína Von Sohsten. Parto nosso de cada dia um olhar sobre as transformações e perspectivas da assistência. Revista de Ciências da Saúde Nova Esperança, João Pessoa, v. 12, n. 1, jun. 2014. 
POZZIO, Maria Raquel. La gineco-obstetricia en México: entre el "parto humanizado" y la violência obstetrica. Revista Estudos Feministas, Florianópolis, v. 24, n. 1, p. 101-117, jan./abr. 2016.

REGIS, Jacqueline Fiuza da Silva; RESENDE, Viviane de Melo. "Daí você nasceu minha filha": análise discursiva crítica de uma carta ao obstetra. DELTA, São Paulo, v. 31, n. 2, p. 573-602, dez. 2015.

SÃO PAULO (Estado). Defensoria Pública do Estado de São Paulo. Núcleo Especializado de Promoção e Defesa dos Direitos da Mulher. Violência obstétrica: você sabe o que é?. São Paulo, 2013.

SEIBERT, Sabrina Lins et al. Medicalização x Humanização: o cuidado ao parto na História. Revista Enfermagem UERJ. Rio de Janeiro, v. 13, n. 2, p. 245-251, maio/ago. 2005. Disponível em: http://www.facenf.uerj.br/v13n2/v13n2a16.pdf>. Acesso em: 26 nov. 2019

SENA, Ligia Moreiras; TESSER, Charles Dalcanale. Violência obstétrica no Brasil e o ciberativismo de mulheres mães: relato de duas experiências. Interface (Botucatu), Botucatu, v. 21, n. 60, p. 209-220, jan./mar. 2017.

SENS, Maristela Muller; STAMM, Ana Maria Nunes de Faria. A percepção dos médicos sobre as dimensões da violência obstétrica e/ou institucional. Interface (Botucatu), Botucatu, v. 23, e170915, 2019b.

SENS, Maristela Muller; STAMM, Ana Maria Nunes de Faria. Percepção dos médicos sobre a violência obstétrica na sutil dimensão da relação humana e médico-paciente. Interface (Botucatu), Botucatu, v. 23, e180487, 2019a.

SILVA, Sílvia Elaine da. Violência obstétrica: uma violação aos direitos humanos da mulher. 2017, 116 f. Trabalho de Conclusão de Curso (Graduação em Bacharelado em Direito) - Universidade Estadual de Ponta Grossa, Ponta Grossa, 2017.

TESSER, Charles Dalcanale; KNOBEL, Roxana; ANDREZZO, Halana Faria de Aguiar; DINIZ, Simone Grilo. Violência obstétrica e prevenção quaternária: o que é e o que fazer. Revista Brasileira de Medicina de Família e Comunidade, v. 10, n. 35, p. 1-12, abr./jun. 2015.

VENEZUELA. Ley 38.668, de 23 de abril de 2007. Ley Orgánica sobre el Derecho de las Mujeres a una Vida Libre de Violência. Disponível em: https://www.acnur.org/fileadmin/Documentos/BDL/2008/6604.pdf. Acesso em: 21 maio 2019.

VENTURI, Gustavo; GODINHO, Tatau (orgs.). Mulheres brasileiras e gênero nos espaços público e privado: uma década de mudanças na opinião pública. São Paulo: Ed. Fundação Perseu Abramo, 2013. 
ZORZANELLI, Rafaela Teixeira; CRUZ, Murilo Galvão Amancio. O conceito de medicalização em Michel Foucault na década de 1970. Interface (Botucatu). Botucatu, v. 22, n. 66, p. 721-731, set. 2018. 